\title{
Comparative Study of Antibacterial Activity of Juice and Peel Extract of Citrus Fruits
}

\author{
Alisha Shakya ${ }^{1}$, Bhawana Luitel ${ }^{1}$, Pragati Kumari ${ }^{1}$, Ritu Devkota ${ }^{1}$, Puspa Raj Dahal ${ }^{2}$, \\ Richa Chaudhary ${ }^{*}$ \\ ${ }^{1}$ Department of Microbiology, D.A.V. College, Dhobighat, Lalitpur \\ ${ }^{2}$ Department of Microbiology, Tri Chandra College, Kathmandu, Nepal
}

*Corresponding author: Richa Chaudhary, Department of Microbiology, D.A.V. College, Dhobighat, Nepal; E-mail: san143ric@yahoo.com

\section{ABSRTACT}

Objectives: This study was aimed to compare the antibacterial activity of peel and juice extracts of citrus fruits.

\begin{abstract}
Methods: The antibacterial activity of juice and peel extract of five selected citrus fruits [C1- Citrus reticulata (mandarin orange), C2- Citrus limetta (sweet lime), C3-Citrus aurantifolia (lime), C4- Citrus limon (lemon) and C5- Citrus maxima (pommelo)] on three Gram positive and five Gram negative bacterial strains were examined. The juice and peel extract of citrus fruits was obtained by using absolute ethanol. The obtained extracts were dissolved in $1 \mathrm{ml} 10 \% \mathrm{v} / \mathrm{v}$ DMSO which was taken to carry out the antibacterial susceptibility assay using agar well diffusion method.
\end{abstract}

Results: The peel extracts of $\mathrm{C} 1$ and $\mathrm{C} 2$ were found to be more effective against the given Gram-positive bacteria than the juice extracts with maximum zone of inhibition (20.33 \pm 1.527$)$ and $(15.33 \pm 0.577)$ against Bacillus spp respectively. While the juice extracts of C3 and C4 were more effective against both Gram positive and negative bacteria than their peel extracts with maximum zone of inhibition (26.66 \pm 1.15$)$ against $S$. aureus ATCC 25923 and (20 \pm 1$)$ against E. coli ATCC 25922 respectively. The juice extract of C5 was found to be more effective against both Gram positive and negative bacteria than its peel extract with maximum zone of inhibition $(18.66 \pm 1.154)$ against E. coli ATCC 25922 except for Bacillus spp in which peel extract showed maximum zone of inhibition i.e. $(15 \pm 1)$

Conclusion: This study suggests that these juice and peel extracts may have beneficial antibacterial roles that can be exploited in controlling unwanted bacterial growth.

Key words: Citrus fruits, Phytochemicals, Antibacterial susceptibility

\section{INTRODUCTION}

Citrus fruits belong to the family of Rutaceae. They consist of about 140 genera and 1,300 species, and are one of the major fruit tree crops grown throughout the world. Citrus juices are consumed not only because of their nutritional value but also due to their special flavor. Fruit juice consumption is beneficial for the maintenance of good health and prevention of diseases. The positive health benefits of juices have been ascribed in part to Vitamin C (ascorbic acid), the major vitamin found in fruits and vegetables (Boudries et al. 2012; Rekha et al. 2012). Citrus fruits are also known

Date of Submission: November 6, 2019

Published Online: December, 2019 to contain phytochemicals (bioactive compounds) such as phenolic, flavonoids, vitamins, and essential oils. Multiple solvents can be employed for the desired yield of phytochemicals. These phytochemicals are believed to be responsible for wide range of protective health benefits including anti oxidative, anti-inflammatory, antitumor, and antimicrobial activities (Aruoma et al. 2012; Karimi et al. 2012). Traditionally it is used to soothe sore throats, indigestion, relieve intestinal gas and bloating, resolve phlegm and as an additive for flavoring to our foods (Nicolosi et al. 2000; Adham et al. 2000).

Date of Acceptance: December 4, 2019

DOI: https:/ / doi.org/10.3126/tujm.v6i0.26589 
Bacterial infections are one of the prominent causes of health problems, physical disabilities and mortalities around the world. Due to the presence of wide range of phytochemicals, medicinal plants are believed to provide a safer and cost-effective way of treating bacterial infections. The antibacterial activity of natural products from medicinal plants is applicable for the treatment of bacterial, fungal and viral diseases. Even though pharmacological industries have produced a number of new antibiotics in the last three decades, resistance to these drugs by microorganisms has increased (Bernhoft 2010). Secondary metabolites or phytochemicals such as phenols, flavonoids, alkaloids, terpenoids, and essential oil have proved to be responsible for the antimicrobial activity of plants (Hwang et al. 2001). Phenol and polyphenol group of compounds consist of thousands of diverse molecules with heterogeneous structure with common feature of having one or more phenol ring. Several workers have reported that phenolic compounds such as gallic acid, coumarins, polyphenols, caffeic acid, cinnamic acid, pyrogallol, eugenol show antimicrobial activity against virus, bacteria and fungi (Saify et al. 2005).The present study aimed to investigate antibacterial properties of juice and peel extract of Citrus reticulata, Citrus limetta, Citrus aurantifolia, Citrus limon and Citrus maxima using agar well diffusion method against some Gram positive bacteria (Bacillus spp, Staphylococcus aureus ATCC 25923, Staphylococcus aureus) and Gram negative bacteria (Escherichia coli ATCC 25922, Escherichia coli, Salmonella Typhi, Klebsiella pneumoniae ATCC 13883, Pseudomonas aeruginosa)

\section{MATERIALS AND METHODS}

Five different varieties of unripe raw citrus fruits named as Lime (Citrus aurantifolia), Lemon (Citrus limon), Pommelo (Citrus maxima), Sweet lime (Citrus limetta), and Mandarin orange (Citrus reticulata) was collected from the local market of Lagankhel, Lalitpur in the month of November. Eight microorganisms were used in this study, consisting of three Gram positive (Staphylococcus aureusATCC 25923, Staphylococcus aureus and Bacillus spp), and five Gram negative (Pseudomonas aeruginosa, Escherichia coli ATCC 25922, Escherichia coli, Klebsiella pneumoniae ATCC 13883, and Salmonella Typhi). All microorganisms were obtained from MED Micro Lab, Kathmandu, Nepal.The study was conducted in the microbiological laboratory, Department of Microbiology, DAV College. The study was conducted from $12^{\text {th }}$ November- $18^{\text {th }}$ February (3 months) 2018/19.

Method described by Hegazy and Ibrahium (2012) was followed with slight modification. The fruits were washed thoroughly after collection by in distilled water. After washing, the peels were separated and oven dried at $55^{\circ} \mathrm{C}$ and after they were completely dried, they were finely crushed into coarse powder with the help of blender and preserved at room temperature (RT) for future use. On the other hand, pulp of fruits was blended using blender to obtain juice. Both the samples i.e. juice and peel powder were extracted by absolute ethanol $(10 \mathrm{gm}$ powder mixed with $100 \mathrm{ml}$ ethanol for peel extract and $10 \mathrm{ml}$ juice in $90 \mathrm{ml}$ ethanol for juice extracts) and the mixture was kept at $30^{\circ} \mathrm{C}$ for 72 hours with constant agitation and the extract was then filtered through Whatman No.1 filter papers. The filtrate was then centrifuged at 4000rpm for $15 \mathrm{~min}$. The solution was then evaporated at $50^{\circ} \mathrm{C}$ until a sticky mass was obtained that was weighed and dissolved in an aliquot of $1.0 \mathrm{ml}$ of $10 \% \mathrm{v} / \mathrm{v}$ Dimethyl sulfoxide (DMSO). The mass was stored at $4^{\circ} \mathrm{C}$ until further use. The samples were coded as [C1: Mandarin orange, C2: Sweet lime, C3: Lime, C4: Lemon, and C5: Pomelo]. Yields were estimated according to the method described by Prasani et al. (2005).

The agar well diffusion method was performed to analyze the antibacterial activity against the test organisms. The plant extract sample was prepared by dissolving $1000 \mathrm{mg}$ of plant extract into $1 \mathrm{ml}$ of $10 \%$ DMSO and for control sample $10 \%$ DMSO was used. The plates were incubated at $37^{\circ} \mathrm{C}$ for 24 hours. Antibacterial activity was evaluated by measuring the diameter of the zone of inhibition (ZOI) around the well. The assay was repeated thrice for concurrent readings.

The yields of extracts were calculated in percentage and the mean and standard deviation of the three readings of antibacterial susceptibility assay was calculated using Microsoft excel 2007. The data are characterized in the form of bar diagram and in tables.

\section{RESULTS}

\section{Percentage yield of extracts}

Using ethanol as solvent, the greatest yield of phytochemical extract from juice was obtained from C5 (13.43\%) and least from C4 (8.8\%). From the peel, the greatest yield obtained was of $\mathrm{C} 1(25.7 \%)$ and the least was of C5 (16.6\%). 


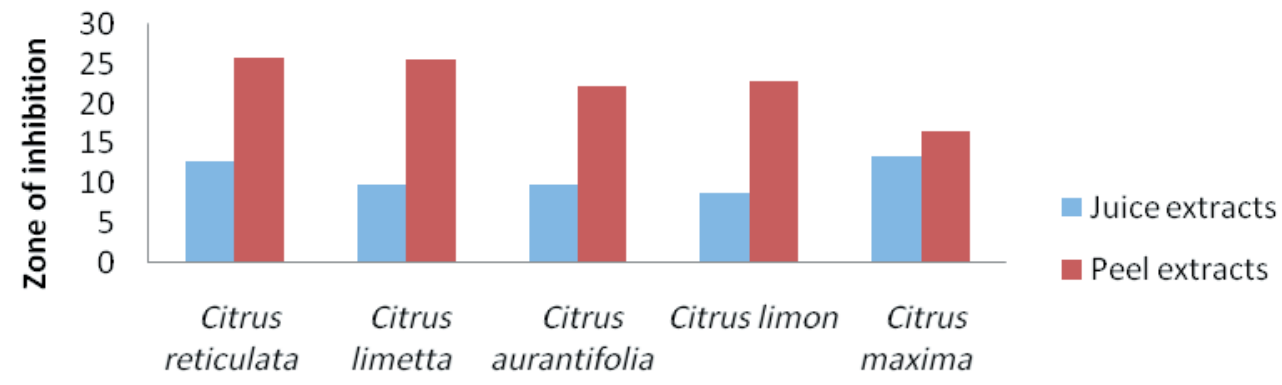

Name of Citrus Fruits

Figure 1: Graph showing yield of extract of citrus fruits

Antibacterial activity of Citrus reticulata extracts against selected bacterial strains

The peel extract of $\mathrm{C} 1$ was found to be more effective against the Gram-positive bacteria than its juice extract with maximum zone of inhibition (20.33 \pm 1.527$)$ against
Bacillus spp. Among the Gram-negative bacteria, the juice extract of $\mathrm{C} 1$ was found to be more effective than its peel extract with maximum zone of inhibition (11.33 \pm 1.154$)$ against Klebsiella pneumoniae ATCC 13883 while $10 \%$ DMSO didn't show any zone of inhibition.

Table 1: Antibacterial activity of Citrus reticulata extracts against selected bacterial strains

\begin{tabular}{lcc}
\hline \multicolumn{1}{c}{ Organism } & \multicolumn{2}{c}{ Diameter of zone of inhibition in mm } \\
\cline { 2 - 3 } & Juice extracts (Mean \pm S.D) & Peel extracts (Mean \pm S.D) \\
\hline Bacillus spp & $11.67 \pm 0.577$ & $20.33 \pm 1.527$ \\
S. aureus ATCC 25923 & $8.33 \pm 0.577$ & $12 \pm 1$ \\
S. aureus & $10.33 \pm 1.528$ & $14.66 \pm 1.154$ \\
E. coli ATCC 25922 & $11 \pm 1$ & 0 \\
E. coli & $9.33 \pm 0.577$ & 0 \\
S. Typhi & $9.66 \pm 1.527$ & 0 \\
P. aeruginosa & $9.33 \pm 0.577$ & 0 \\
K. pneumoniae ATCC13883 & $11.33 \pm 1.154$ & $10.33 \pm 1.527$ \\
\hline
\end{tabular}

Antibacterial activity of Citrus limetta against selected bacterial strains

The peel extract of C2 was found to be more effective against the Gram-positive bacteria than its juice extract with maximum zone of inhibition (15.33 \pm 0.577$)$ against Bacillus spp. Among the Gram negative bacteria, the juice extract of $\mathrm{C} 2$ was found to be more effective than its peel extract against the four other bacteria chosen with maximum zone of inhibition (8.33 \pm 2.081$)$ against E. coli ATCC 25922, except Klebsiella pneumoniae ATCC 13883 on which the peel extract was more effective with zone of inhibition $(10.33 \pm 1.527)$ while $10 \%$ DMSO didn't show any zone of inhibition.

Table 2: Antibacterial activity of Citrus limetta against selected bacterial strains

\begin{tabular}{lcc}
\hline \multicolumn{1}{c}{ Organism } & \multicolumn{2}{c}{ Diameter of zone of inhibition in mm } \\
\cline { 2 - 3 } & Juice extracts $($ Mean \pm S.D) & Peel extracts $($ Mean \pm S.D) \\
\hline Bacillus spp & $10.33 \pm 0.577$ & $15.33 \pm 0.577$ \\
S. aureus ATCC 25923 & $6.33 \pm 1.527$ & $11.33 \pm 1.154$ \\
S. aureus & $7.66 \pm 0.577$ & $11.33 \pm 1.154$ \\
E. coli ATCC 25922 & $8.33 \pm 2.081$ & 0 \\
E. coli & $7 \pm 1$ & 0 \\
S. Typhi & $5 \pm 1$ & 0 \\
P. aeruginosa & $6.33 \pm 1.527$ & 0 \\
K. pneumoniae ATCC13883 & 0 & \\
\hline
\end{tabular}


Antibacterial activity of Citrus aurantifolia against selected bacterial strains

The juice extract of C3 was found to be more effective against the Gram-positive bacteria than its peel extract with maximum zone of inhibition $(26.66 \pm 1.15)$ against
S. aureus ATCC 25923. Among the Gram-negative bacteria, the juice extract of $\mathrm{C} 3$ was found to be more effective than its peel extract with maximum zone of inhibition (25 \pm 1 ) against E. coli ATCC 25922 while 10\% DMSO didn't show any zone of inhibition.

Table 3: Antibacterial activity of Citrus aurantifolia against selected bacterial strains

\begin{tabular}{lcc}
\hline \multirow{2}{*}{ Organism } & \multicolumn{2}{c}{ Diameter of zone of inhibition in mm } \\
\cline { 2 - 3 } & Juice extracts (Mean \pm S.D) & Peel extracts $($ Mean \pm S.D) \\
\hline Bacillus spp & $23 \pm 1$ & $23.33 \pm 1.154$ \\
S. aureus ATCC 25923 & $26.66 \pm 1.15$ & $21.33 \pm 1.154$ \\
S. aureus & $24 \pm 1$ & $21.66 \pm 1.527$ \\
E. coli ATCC 25922 & $25 \pm 1$ & $21.33 \pm 1.154$ \\
E. coli & $21.33 \pm 1.527$ & $8.33 \pm 0.577$ \\
S. Typhi & $21.33 \pm 1.154$ & $20.66 \pm 1.154$ \\
P. aeruginosa & $20.66 \pm 1.154$ & $9.33 \pm 1.154$ \\
K. pnuemoniae ATCC13883 & $17 \pm 1$ & $18 \pm 2$ \\
\hline
\end{tabular}

Antibacterial activity of Citrus limon against selected bacterial strains

The juice extract of C3 was found to be more effective against the Gram-positive bacteria than its peel extract with maximum zone of inhibition (19.33 \pm 0.577$)$ against
S. aureus ATCC 25923. Among the Gram-negative bacteria, the juice extract of $\mathrm{C} 3$ was found to be more effective than its peel extract with maximum zone of

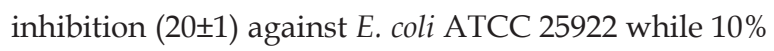
DMSO didn't show any zone of inhibition.

Table 4: Antibacterial activity of Citrus limon against selected bacterial strains

\begin{tabular}{lcc}
\hline \multirow{2}{*}{ Organism } & \multicolumn{2}{c}{ Diameter of zone of inhibition in mm } \\
\cline { 2 - 3 } & Juice extracts (Mean \pm S.D) & Peel extracts (Mean \pm S.D) \\
\hline Bacillus Spp & $19.66 \pm 1.527$ & $16 \pm 1$ \\
S. aureus ATCC 25923 & $19.33 \pm 0.577$ & $17.66 \pm 0.577$ \\
S. aureus & $18.33 \pm 0.577$ & $9.33 \pm 1.154$ \\
E. coli ATCC 25922 & $20 \pm 1$ & $9 \pm 1$ \\
E. coli & $18.66 \pm 0.577$ & $8.66 \pm 0.577$ \\
S. Typhi & $15.33 \pm 0.577$ & $11 \pm 1$ \\
P. aeruginosa & $17.66 \pm 0.577$ & $7 \pm 1$ \\
K. pneumoniae ATCC13883 & $15.66 \pm 0.577$ & $11.33 \pm 1.154$ \\
\hline
\end{tabular}

Antibacterial activity of Citrus maxima against selected bacterial strains

Among Gram positive bacteria, the juice extract of C5 was found to be more effective against the $S$. aureus

ATCC 25923 and S. aureus while its peel extract was more effective against Bacillus spp. Among the Gramnegative bacteria, the juice extract of $\mathrm{C} 5$ was found to be more effective than its peel extract with maximum zone of inhibition (18.66 \pm 1.154$)$ against E. coli ATCC 25922 while $10 \%$ DMSO didn't show any zone of inhibition.

Table 5: Antibacterial activity of Citrus maxima against selected bacterial strains

\begin{tabular}{lcc}
\hline \multicolumn{1}{c}{ Organism } & \multicolumn{2}{c}{ Diameter of zone of inhibition in mm } \\
\cline { 2 - 3 } & Juice extracts (Mean \pm S.D) & Peel extracts (Mean \pm S.D) \\
\hline Bacillus spp & $3 \pm 2.645$ & $15 \pm 1$ \\
S. aureus ATCC 25923 & $17.33 \pm 1.154$ & $6.66 \pm 1.154$ \\
S. aureus & $14.66 \pm 0.577$ & $7.66 \pm 0.577$ \\
E. coli ATCC 25922 & $18.66 \pm 1.154$ & 0 \\
E. coli & $12.66 \pm 1.154$ & 0 \\
S. Typhi & $14 \pm 1$ & 0 \\
P. aeruginosa & $13 \pm 1$ & 0 \\
K. pneumoniae ATCC13883 & $13.33 \pm 1.527$ & $10.66 \pm 1.154$ \\
\hline
\end{tabular}




\section{DISCUSSION}

In this study, peel extracts of Citrus reticulata was found to be more effective than its juice extracts against the Gram-positive bacteria with highest zone of inhibition against the Bacillus spp $(20.33 \pm 1.527)$ while it did not show any zone of inhibition against E. coli, E. coli ATCC 25922, S. Typhi and P. aeruginosa. In case of juice extracts, Bacillus spp showed highest zone of inhibition $(11.67 \pm 0.577)$ and the least zone was showed by E. coli ATCC 25922 and P. aeruginosa (9.33 \pm 0.577$)$. Similar finding was observed from the study by Zainab et al. (2017) who reported the highest zone of inhibition exhibited by peel extract of Citrus reticulata was against S. aureus $(28 \mathrm{~mm})$ while E. coli, S. Typhi, P. aeruginosa were found to be resistant against the peel extracts. The highest zone of inhibition by juice extracts was against $S$. aureus $(22 \mathrm{~mm})$ but it did not show any zone of inhibition against $P$. aeruginosa $(0 \mathrm{~mm})$. In mandarin peels, flavanone glycosides were present in a decreasing sequence, as follows: narirutin>hesperidin>naringin. The presence of higher amount of such flavanone in peel might be the reason behind the effectiveness of peel extract than that of juice (Levaj et al. 2009).

The peel extract of Citrus limetta was more effective against the Gram-positive bacteria than its respective juice extracts. Highest zone of inhibition shown by peel extract was against Bacillus spp $(15.33 \pm 0.577)$ and its effect was absent on E. coli ATCC 25922, E. coli, S. Typhi and $P$. aeruginosa. Juice showed the highest effectiveness against Bacillus spp (10.33 \pm 0.577$)$ and was not effective against K. pneumoniae ATCC 13883(0mm). The juice extract was found to be more effective against all Gram-negative bacteria chosen except for K. pneumoniae ATCC 13883 in which the peel extract was found more effective. Javed et al. (2013) investigate that the tested $C$. limetta had shown nearly equal antimicrobial effects on both Gram positive (B. subtilis, S. aureus ATCC 25923, B. cereus ATCC 14579) and Gram negative (E. coli ATCC 25922, S. typhimurium ATCC 14028) bacterial strains in culture media. However, in this finding most of the Gram-negative bacteria were found to be resistant against peel extract. The reason behind this might be due to the difference in the cell structure of Gram positive and Gram-negative bacteria. Gram negative bacteria possess outer membrane which can act as a barrier for antimicrobials to enter to the cells. Reviews suggest that flavonoids and phenolics were significantly greater in peel than the juice which might be the reason for effectiveness of peel.

The present study found that the juice extract of Citrus aurantifolia was more effective than its respective peel extracts against both Gram positive bacteria and Gramnegative bacteria. The highest zone of inhibition shown by juice extract was against $S$. aureus 25923 (26.66 \pm 1.15 $\mathrm{mm}$ ) and the least against K. pneumoniae ATCC 13883 $(17 \pm 1)$ while the highest zone of inhibition shown by peel extract was against Bacillus spp. $(23.33 \pm 1.154)$ and the least against E. coli $(8.33 \pm 0.577)$. Similar finding on juice extract of Citrus aurantifolia was observed from the study by Aibinu et al. (2007) who reported that the juice extract of Citrus aurantifolia showed highest zone of inhibition against Staphylococcus aureus $(35 \mathrm{~mm})$ and the least against K. pneumoniae ATCC 13883 (16mm). Similarly, Alfarraj et al. (2018) in his experiment found that the peel extract of C. aurantifolia showed highest zone of inhibition against S. aureus $(18.5 \mathrm{~mm})$ and the least against E. coli (15mm). Pathan et al. (2012) observed that the phytochemicals such as flavonoides, steroids and tannins were absent in ethanolic extract of peel whereas they were present in juice. The presence of these chemical constituents underscores the effectiveness of juice extract of Citrus aurantifolia than that of peel.

In this study, the juice extract of Citrus limon was more effective than its respective peel extracts against both Gram positive and Gram-negative bacteria. The highest zone of inhibition shown by juice extract was against Bacillus spp (19.66 \pm 1.527$)$ and the least was against K. pneumonia ATCC 13883(15.66 \pm 0.577$)$ while highest zone of inhibition shown by peel extract was against S. aureus ATCC $25923(17.66 \pm 0.577)$ and the least against $P$. aeruginosa $(7 \pm 1)$. Okeke et al. (2015), in his study found that the zone of inhibition by $C$. limon juice extract against Bacillus spp was $19 \mathrm{~mm}$. Present study is in agreement with the above findings. In the study carried out by Sokovic et al. (2007), the highest zone of inhibition shown by the peel extract of C. limon was against $S$. aureus $(16 \mathrm{~mm})$ and $P$. aeruginosa was found resistant to it. His finding was quite similar to that of present study. Pandey et al. (2011) in his study reported that the peel of C. limon consists of tannins, reducing sugars, flavonoides but there is absence of saponins and phlobatannins. The juice extract contained all of these phytochemicals and thus the juice extract showed maximum inhibition than peel. 
The juice extract of $C$. maxima had highest zone of

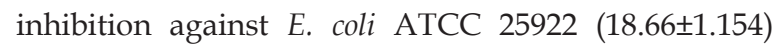
whereas lowest zone of inhibition against Bacillus $\operatorname{spp}(3.0 \pm 2.645)$ while the highest zone of inhibition shown by peel extract was against Bacillus spp $(15 \pm 1)$ and there was no zone of inhibition against E. coli, E. coli ATCC 25922, S.Typhi, P. aeruginosa. Swarnami et al. (2013), in his study found that the zone of inhibition by C. maxima juice extract against $E$. coli was $22 \mathrm{~mm}$ and against Bacillus spp was $24 \mathrm{~mm}$. The zone of inhibition shown by Bacillus spp didn't match to that of present findings. This difference might be due to the difference in the species of Bacillus chosen for study as the different species have their own susceptibility against the different antibacterial substances.

\section{CONCLUSION}

Antibacterial activity shown by the juice and peel extracts of Citrus fruits guided that more pure form of these extract can be more effective agent and can be used as alternative for the treatment of infections associated to the studied microorganisms.

\section{ACKNOWLEDGEMENTS}

We would like to thank all faculty members of Department of Microbiology, D.A.V College for providing all the essential facilities to carry out the work successfully and MED Micro Laboratory Nepal for providing us the test organisms.

\section{CONFLICT OF INTEREST}

The authors declare no conflict of interest.

\section{REFERENCES}

Adebayo Tayo BC, Akinsete T and Odeniyi OA (2016). Phytochemical composition and comparative evaluation of antimicrobial activities of the juice extract of Citrus aurantifolia and its silver nano particles. Nigeria Journal of Pharmacology 12(1): 5964.

Adham T, Andrea V and Nadia N (2000). Comparative Antimicrobrial activity of peel and juice extract of citrus fruits growing in Kurdistan/Iraq. American Journal of Microbiological Research 3(5): 155-159.

Alfarraj D, Manal M, Al K and Nadine MSM (2018). Correlation of phenolic content and antibacterial activity of dried lime extracts against human pathogen. Biomedical Research 29 (16): 3239-3242.

Altemimi A, Lakhsassi NB, Ahar louei A, Watson DG and Lightfoot DA (2017). Phytochemicals: extraction, isolation and identification of bioactive compounds from plant extracts. Plants (6): 42-43.

Aruoma OI, Landes B, Ramful D, Bourdond E., Neergheen V and Wagnerf K (2012). Functional benefits of citrus fruits in the management of diabetes. Prev Med 54: S12-S16.

Boudries H, Madani K, Touati N, Souagui S, Medouni S and Chibane M (2012). Pulp antioxidant activities, mineral contents and juice nutritional properties of Algerian Clementine Cultivars and Mandarin. Afr J Biotechnol 11: 4258-4267.

Burkill HM (1997). The useful plants of West Tropical Africa. Royal Botanic Gardens, Kew, UK, 4: 969.

Chakraborty A, Devi RK, Rita S, Sharatchandra K and Singh TI (2004). Preliminary studies on ant-inflammatory and analgesic activities of Flavonoids Spilanthesacmella in experimental animals. Indian J Pharmacol 36: 148-150.

Do QD, Awijaya AE, Njuyen PLT, Huynhl H, Soetaredjo FE, Ismadji S and Ju YH (2014). Effect of extraction solvents on total phenol content, total flavonoids content and antioxidant activity of Limnophila aromatic. Journal of Food and Drug Analysis 22(3): 296-302

Dubey D, Balamurugan K, Agrawal RC, Verma R and Jain R (2011). Evaluation of antibacterial and antioxidant activity of methanolic and hydromethanolic extract of sweet orange peels. Recent Res Sci Technol 3(11): 22-25.

Fessenden RJ and Fessenden JS (1982). Organic chemistry. Willard Grant Press, Boston, Mass U. K. flavonoids in Pulp and Peel of Mandarin Fruits, ACS 2.

Geissman TA (1963). Flavonoid compounds, tannins, lignins and related compounds. Comprehensive Biochemistry 9: 213-250.

Ghasemi K, Ghasemi Y and Ebrahimzadeh AM (2009). Antioxidant activity, phenol and flavonoid contents of 13 citrus species peels and tissues. Pak J Pharm Sci 22(3):277-281.

Hegazy AE and Ibrahium MI (2012). Antioxidant activities of orange peel extracts. World Applied Sciences Journal 18 (5): 684-688.

Hwang SL, Shih PH and Yen GC (2012). Neuroprotective 
effects of citrus flavonoids. J Agric Food Chem 60: 877-885.

Karimi E, Oskoueian E, Hendra R, Oskoueian A, and Jaafar HZE (2012). Phenolic compounds characterization and biological activities of Citrus aurantium bloom. Molecules 17: 1203-1218.

Khan AA, Mahmood T, Siddiqui HH and Akhtar J (2016). Phytochemical and pharmacological properties on Citrus limetta (Mosambi). Journal of Chemical and Pharmaceutical Research 8(3): 555-563.

Klangpetch W, Phromsurin K, Hannarong K, Wichaphon J and Rungchang S (2016). Antibacterial and antioxidant effects of tropical citrus peel extracts to improve the shelf life of raw chicken drumettes. International Food Research Journal 23(2): 700-707.

Koffi E, Sea T, Dodehe Y and Soro S (2010). Effect of solvent type on extraction of polyphenols from twenty-three ivorian plants. J Anim Plant Sci 550558.

Levaj B, Dragovic V, Bursac D, Krasnici N (2009). Determination of Flavonoids in Pulp and Peel of Mandarin Fruits. Agriculturae Conspectus Scientificus 74 (3): 221-225.

Li Y, Guo C, Yang J, Wei J, Xu J and Cheng S (2006). Evaluation of antioxidant properties of pomegranate peel extract in comparison with pomegranate pulp extract. Food Chem 96: 254-260.

Mishra RP, Yadav S and Anjali K (2012). Study of Antimicrobial Activities of Citrus limetta. Journal of Pharmaceutical and Biomedical Sciences 19 (15):14.

Okeke M, Okoli A, Eze E, Ekwume G, Okosa E and Iroegbu C (2015). Antibacterial activity of Citrus limonum fruit juice extract. Pak J Pharm Sci 28(5): 1567-1571.

Okwu DE (2005). Phytochemicals, vitamins and minerals contents of two nigerian medicinal plants. International $J$ Molecular Medicine and Advance Sciences 1: 375-381.

Pathan R, Gali P, Pathan P, Gowtham T and Pasupuleti
S (2012). In vitro antimicrobial activity of Citrus aurantifolia and its phytochemical screening. Asian Pacific Journal of Tropical Disease S328-S331.

Prashani ME, Geun TP, Young DL, Sejae K, Sang J and Jehee L (2005). Antioxidative activity extract from fenugreek seeds. Pak J Anak Environ Chem 9(2): 78-83.

Ravi KU, Dwivedi P and Ahmad S (2010). Screening of antibacterial activity of six plants essential oils against pathogenic bacterial strains. Asian J Med Sci 2: 152-158.

Roger GDP (2002). Encyclopedia of medicinal plants, education and health library. Safeliz SL Spsin, 1: 153-154.

Saify ZS, Farhad J, Mushtaq N and Noor F (2005). Antibacterial activity of 1-methyl-7- methoxybetacarboline and its phenacyl and coumarin analogues. Pakistan Journal of Pharmaceutical Science 18(3): 39-41

Silalahi J (2002). Anticancer and health protective properties of Citrus fruit components. Asia Pac J Clin Nutr 11: 79-84.

Soković M, Marin P, Brkić D and Griensven L (2007). Chemical composition and antibacterial activity of essential oils of ten aromatic plants against human pathogenic bacteria. Global Science Books 1(1): 2-5.

Swarnamoni D, Mukundam B and Shagufa A (2013). Antibacterial activity of the ethanolic extract of leaves of citrus maxima (Burm,) Merr on Escherichia coli and Pseudomonas aeruginosa. Asian Journal of Clinical and Pharmaceutical Research 6(4): 136-139.

Wong PYY and Kitts DD (2006). Studies on the dual antioxidant and antibacterial properties of parsley (Petroselinum crispum) and cilantro (Coriandrum sativum) extracts. Food Chem 97: 505-515.

Zainab AGC and Kadhim NK (2013). Antimicrobial activity of different aqueous lemon extracts. Journal of Applied Pharmaceutical Science 3(6): 7478. 